Cuadernos de Ilustración y Romanticismo

Revista Digital del Grupo de Estudios del Siglo XVIII

Universidad de Cádiz / ISSN: 2173-0687

$\mathrm{n}^{\circ} 24(2018)$

\title{
BEATRIZ MANRIQUE DE LARA ALBERRO, MARQUESA DE GARCÍA DEL POSTIGO, AUTORA DE LA PENSADORA GADITANA BAJO EL PSEUDÓNIMO DE BEATRIZ CIENFUEGOS
}

\author{
Cinta Canterla* \\ (Universidad Pablo de Olavide de Sevilla)
}

Recibido: 17-8-2018 / Revisado: 17-8-2018

Aceptado: 17-8-2018 / Publicado: 20-12-2018

\begin{abstract}
Resumen: Este artículo analiza una amplia documentación y concluye que Beatriz Manrique de Lara Alberro, Marquesa de García del Postigo, fue la autora del periódico La Pensadora Gaditana y de la traducción de la tragedia Zaüre de Voltaire publicada con el título de Combates de amor y ley. En el primer caso, bajo el pseudónimo de «Beatriz Cienfuegos», compuesto por su propio nombre y un anagrama a partir del nombre de su hija; en el segundo, bajo otro pseudónimo formado con el nombre de su marido y su hijo, «Juan Francisco del Postigo», transformado en el anagrama Fernando Jugaccis Pilotos.

Palabras Clave: Ilustración, Periodismo, La Pensadora Gaditana, Beatriz Cienfuegos, Ttraducción, Voltaire, Beatriz Manrique de Lara, Marquesa de García del Postigo.
\end{abstract}

\section{BEATRIZ MANRIQUE DE LARA ALBERRO, MARCHIONESS OF GARCÍA DEL POSTIGO, AUTHOR OF LA PENSADORA GADITANA UNDER PSEUDONYM «BEATRIZ CIENFUEGOS»}

AвSTRACт: This paper analyzes a large amount of data and concludes that Beatriz Manrique de Lara Alberro, Marchioness of García del Postigo, was author of the newspaper $L a$ Pensadora Gaditana and translator of the Voltaire's tragedy Zaïre, published as Combates de amor y ley. In the first case, under the pseudonym of «Beatriz Cienfuegos», composed by her own name and an anagram from the name of her daughter; in the second, under another pseudonym formed by the names of her husband and one of her sons, «Juan Francisco del Postigo», transformed into the anagram «Fernando Jugaccis Pilotos».

Keywords: Enlightenment, Journalism, La Pensadora Gaditana, Beatriz Cienfuegos, Translation, Voltaire, Beatriz Manrique de Lara, Marchioness of García del Postigo.

* Cinta Canterla pertenece al Grupo de Estudios del Siglo XVIII, con cabecera en la Universidad de Cádiz. Es igualmente investigadora del proyecto $\mathrm{I}+\mathrm{D}+\mathrm{I}$ «El desván de la razón: cultivo de las pasiones, identidades éticas y sociedades digitales»: PAIDESOC (FFI $2017-82535-\mathrm{P}$ ), con cabecera en el Instituto de Filosofía del CSIC en Madrid $\mathrm{y}$ financiado por el MINECO. 
En 1999 escribí en esta misma revista un artículo titulado «El problema de la autoría de La Pensadora Gaditana» (Canterla, 1999). En él me hacía eco de la tesis de Manuel Ravina según la cual, una referencia que él mismo encontró en el Diario Mercantil de 3 de octubre de 1829 establecía una curiosa conexión entre el periódico publicado en Cádiz sesenta y seis años antes y una traducción —al modo de las realizadas en la Ilustración: una versión - de la tragedia Zaïre de Voltaire, aparecida en 1765 a nombre de Fernando Jugaccis Pilotos, en la misma imprenta ${ }^{1}$ de la que salió La Pensadora: Combates de amor y ley.

Ya desde el propio siglo xviII la crítica atribuía esos Combates a un desconocido Juan Francisco del Postigo, del que Fernando Jugaccis Pilotos sería un anagrama. Así puede verse, por ejemplo, en la obra de Juan Sempere y Guarinos Ensayo de una biblioteca española de los mejores escritores del reinado de Carlos III. ${ }^{2} \mathrm{Y}$ aunque la cita del Diario Mercantil sobre la que llamó la atención Ravina hablaba en realidad de un tal D. N. del Postigo, este excelente investigador señaló la conexión como un elemento a explorar, sin sacar más conclusiones precipitadas.

Scott Dale, en la edición que hizo de La Pensadora Gaditana en 2005, se hizo eco de lo ya indicado por mí en 1999 con respecto al descubrimiento en el Diario Mercantil de la mencionada cita por parte de Ravina (que nunca llegó a publicarlo, pero al que cité porque la honestidad intelectual obliga a revelar las fuentes, aunque sean orales). Y a partir de ese momento su hipótesis de trabajo fue que Juan Francisco del Postigo, un fraile, debió ser el probable autor de la traducción de Voltaire y de La Pensadora. A pesar de que no exista — hasta la fecha— ningún documento histórico que acredite la existencia de un fraile o sacerdote con ese nombre en el Cádiz del siglo xviıI.

Mi apuesta en el artículo de 1999 fue seguir investigando la cuestión de la autoría de La Pensadora Gaditana con cautela y prudencia. Anticipo ahora aquí algunos de los resultados a los que he llegado. Comencemos — aunque como veremos más abajo, no es estrictamente necesario para la argumentación - con la afirmación del Diario Mercantil según la cual «el verdadero autor de este periódico, que se escribió en contraposición del Pensador matritense, fue D. N. del Postigo». ${ }^{3}$ Inicialmente yo desconocía, como es el caso de otros investigadores que han considerado la cita, que estaba ante una convención para aludir a un nombre que o no se sabe o no se quiere mencionar. Pensé que las iniciales corresponderían a «Don» (D.) y después a algún nombre, por ejemplo Nicolás (N.), y busqué documentos históricos y literarios del siglo XviII español donde apareciese ese nombre u otro similar junto con el apellido "del Postigo», con resultado negativo. Leí entonces todos los números del Diario Mercantil correspondientes al contexto histórico de esa afirmación aparecida en el número concreto de i829, y me llamó la atención un hecho: que los nombres de las personas citadas nunca aparecían con iniciales, sino completos, lo que hacía excepcional ese «D. N.». Comencé entonces a investigar en la dirección de siglas utilizadas en la época, que indicaran cargos eclesiásticos, militares, etc., sin resultado alguno tampoco. Hasta que topé con un interesante documento de la Armada que me permitió hacer una hipótesis fiable de qué era D. N., pues ilustra bien el uso de estas dos siglas para expresar que se desconoce un nombre.

Se trata de Ordenanzas generales de la Armada Naval. Parte primera. Sobre la gobernación militar y marinera de la Armada en general y usos de sus fuerzas en la mar, Tomo II, publicadas en Madrid, en la Imprenta Real, en I793. En estas Ordenanzas aparecen

I La Imprenta Real de Marina.

2 Tomo III. Madrid, Imprenta Real, I786, p. 2I8. En el tomo IV, publicado al año siguiente, en la p. I86, atribuye La Pensadora a Da Beatriz Cienfuegos, sin establecer conexión alguna entre la traducción y el periódico.

3 Diario Mercantil de Cádiz, del sábado 3 de octubre de r829, p. 3. Es el no 48 ro. 
numerosos modelos de informes y documentos para ser utilizados en los trámites administrativos de la Armada española. Como son modelos genéricos, que ya después serían, en la práctica, elaborados con las referencias a nombres concretos, se utilizan dos siglas: $\mathrm{N}$., para referirse a nombres incógnitos de trabajadores (marinería, carpinteros, etc.), de barcos y de ciudades, por ejemplo, «El marinero N., hijo de N. y N., nacido en N., que iba en el barco N.»; y D. N. para oficiales y otros caballeros, es decir, Don N. Este último uso, el que aquí nos interesa, puede ilustrarse, entre otros, con el siguiente texto, que propone cómo se podría redactar un informe (la cursiva es de la propia fuente) relativo a unos oficiales:

por ejemplo, que en el mes de octubre quedaron pendientes los pagos del sueldo abonado a los Tenientes de Fragata D. N. y D. N. por ausencia inmediata al libramiento; que aunque en la relación de febrero no están las firmas del Brigadier D. N., porque se hallaba enfermo y murió de resultas, y del Alférez de Navio D. N., que estaba destacado en los almacenes de pólvora. ${ }^{4}$

Pero la convención no se limita a España. Me la había encontrado antes —aunque no lo relacioné en su momento- en la dedicatoria que Hamann realiza en I759 de su Evocación de Sócrates, cuando el autor la destina a «Nemo», la persona desconocida del público a la que va a llegar la obra, siendo la convención culta utilizada para referirse a un alguien del que no sabe el nombre (Hamann, 2015: 2I). ${ }^{5}$ Sea como sea, ya significase la sigla N. utilizada en este ejemplo tomado de la Armada «Nemo», esto es, nadie en concreto, o simplemente «Nombre», en el sentido de «aquí va un nombre, que se desconoce» (creo que debía ser esto último, puesto que también va a referida a barcos y ciudades), lo que sí es cierto es que, según esa convención, decir «D. N. del Postigo» sería algo semejante a decir «un tal del Postigo». Lo que más coloquialmente hoy se diría «D. Nosequién del Postigo», alguien de la familia del Postigo. ${ }^{6}$

Esta hipótesis con respecto a la cita del Diario Mercantil — que su autor se acoge a la convención referida - no es indispensable para el grueso de mi argumentación sobre la autoría de La Pensadora, pero he querido empezar por aquí porque avala bien la intuición de Ravina de que es posible establecer una conexión entre la cita y el nombre «Juan Francisco del Postigo", relacionando la autoría del periódico con la traducción de la tragedia, a pesar de que no coincidan las iniciales; y porque sale al paso de algunos errores que se deslizan en las publicaciones al respecto por desconocimiento. $Y$ efectivamente, que no parece ser necesaria lo demuestra el hecho de que los investigadores que han establecido la conexión entre la cita y el nombre «Juan Francisco del Postigo» han pasado por alto la no coincidencia, sin referirse a la convención arriba aludida y acogiéndose implícita o explícitamente a la suposición más fácil de que el autor del texto del Diario simplemente se habría confundido al escribir N. como inicial de nombre, en vez de J. F., las del supuesto autor de Combates de amor y ley. Una decisión que no ha convencido a todos, acogiéndose otros investigadores a la aparente diferencia entre «D. N. del Postigo» y «Juan Francisco del Postigo» para negar la conexión. Frente a ambas posiciones, sostengo que puede afirmarse con verosimilitud que no se trata de un error ni tampoco de una

${ }_{4}$ Tomo II, p. 4I5. También se usa D. N. en las pp. 3I3 y 4I6, para referirse siempre a nombres desconocidos de oficiales de la armada. Se usa N., en cambio, en pp. 30I, 3I3, 4I3, para nombres desconocidos de trabajadores, de sus padres, de ciudades y pueblos, y de barcos. Igualmente ocurre en el tomo I (Madrid, Imprenta de la viuda de Don Joachin Ibarra, I793): se emplea de D. N., en p. I32, y de N. en pp. 255 y 256.

5 Utiliza «Nemo», en latín, y «Niemand», en alemán.

6 Fernando Durán me confirma que es una conocida convención utilizada desde antiguo, que aparece indicada, por ejemplo, en el Diccionario de Terreros en r787 en la entrada de la letra «N»: «La N en los escritos significa un nombre que se ignora, no se quiere, o no conviene decir, y se lee en Castellano $N$ tal, o Fulano». 
evidencia que acredite la desvinculación, sino de una afirmación que, al hablar de «un tal del Postigo», permite establecer la relación.

Voy a argumentar a partir de ahora a favor precisamente de esa hipótesis: la de que $L a$ Pensadora Gaditana y Combates de amor y ley fueron escritos por la misma persona y que este alguien perteneció a la familia «del Postigo». Más concretamente: voy a sostener que fue la gaditana Beatriz Manrique de Lara Alberro, Marquesa de García del Postigo (en la fecha de publicación de las obras, ya Marquesa viuda), la autora del periódico y de la tragedia. El periódico, escrito bajo el pseudónimo de Beatriz Cienfuegos; 7 y la traducción de la tragedia, con el pseudónimo de Juan Francisco del Postigo, tomado del nombre de su marido, Francisco, y uno de sus hijos, Juan, y el apellido de estos, «del Postigo», a partir del cual construyó el anagrama completo «Fernando Jugaccis Pilotos». Porque como veremos a continuación, todos los varones con apellido «García del Postigo» de esa misma familia, su marido Francisco, sus dos cuñados Isidoro y Juan, sus hijos Diego y Juan, miembros de la Armada española, vieron su primer apellido abreviado en numerosas ocasiones - como se puede observar en toda clase de documentos, incluso los oficiales- a simplemente «del Postigo». ${ }^{8}$ Son los únicos «del Postigo» de los que tenemos documentos históricos que avalen su existencia en Cádiz en los años de publicación de La Pensadora Gaditana.

En mi opinión, como en la de otros investigadores, hay efectivamente un vínculo entre La Pensadora Gaditana (1763-1764) y Combates de amor y ley (1765). Pero también con otros dos impresos hasta ahora no mencionados por los que se han ocupado de esta cuestión de la autoría del periódico, y que salieron igualmente de la misma Imprenta Real de Marina. El primero de ellos ve la luz el mismo año que la tragedia, 1765: Relación individual de las operaciones de la escuadra francesa sobre las costas de Berbería, en el mes de junio de este presente año de 1765 ( $I m$ Impresa en Cádiz, en la Imprenta Real de Marina, y reimpresa en Sevilla, en la Imprenta de Manuel Nicolás Vázquez, en Calle de Génova»). ${ }^{9}$ Es una noticia periodística, narrada de modo anónimo a partir supuestamente, según indica el texto, de las informaciones aportadas por un cautivo español que consigue huir de los «moros» durante la escaramuza naval que se cuenta, siendo recogido desde el mar por un barco francés, la fragata la Terpsicore, que lo ha traído a Cádiz (p. 5). Relata en términos reales (puede comprobarse comparando lo dicho en el impreso con lo que realmente ocurrió, cotejando otras fuentes históricas) un ataque desde el mar, por parte de navíos franceses al mando de «D. Luis Duchaffault», ${ }^{10}$ a las costas de la Berbería, en concreto sobre Salé, en lo que hoy es la costa atlántica de Marruecos, y el posterior intento de sitio de Larache.

Una prueba de que el texto del impreso fue recibido por el público como una noticia fiable, y no como un relato subjetivo y literario del suceso (a pesar de que la persona que

7 El posible motivo de índole naval para el apellido Cienfuegos lo veremos más adelante, tomando en consideración una afirmación sobre el mismo que se encuentra en las propias páginas del periódico. Pero además, Cienfuegos es un anagrama incompleto del nombre de su hija. Los anagramas pueden ser completos (si se utilizan todas las letras de un nombre para construir el anagrama), o incompletos (si solo se usan algunas, de forma que el anagrama está contenido en el nombre, pero no lo agota). Las letras de la palabra «Cienfuegos» están en el nombre y apellidos de Francisca, que en la versión abreviada del apellido de sus padres era Francisca del Postigo Manrique, y en la extensa, Francisca de Paula García del Postigo y Manrique de Lara.

8 Puede verse esto, por ejemplo, en los distintos documentos en los que aparecen estos hermanos que se encuentran en la colección de Vargas Ponce. Cf. Pilar San Pío y Carmen Zamarrón (I979: II, 50): el índice onomástico incluye la doble forma del apellido, extensa y abreviada, y remite a las páginas donde se encuentran los documentos).

9 He trabajado con el ejemplar que se encuentra en la Biblioteca Virtual de Andalucía. Según he podido leer con posterioridad, aunque no he podido comprobarlo, en los fondos de Vargas Ponce en la Real Academia de la Historia se encontraría una copia manuscrita individual de este impreso, realizada por él mismo, según indican los catálogos. Cf., por ejemplo, la información facilitada en la obra de Fernández Duro (I897 y ss.: vi, 502). Cito en lo sucesivo con la página de la edición consultada.

Io Se trata de Louis Charles du Chaffault (o Duchaffault) de Besné, a quien el Rey de Francia encargó esta misión contra los piratas de esta zona. 
lo escribió haya ocultado sus fuentes, remitiéndose al referido cautivo) es que lo recogiese como narración fidedigna la Gaceta de Madrid del 23 de julio de 1765, , ${ }^{\text {II }}$ en estos términos: «Los más fundados avisos que se han recibido en esta plaza de las operaciones de la Escuadra Francesa sobre las costas de Berbería, son del tenor siguiente». Y a continuación se cita completo el texto del impreso, entrecomillándolo, sin dar más indicaciones sobre su publicación, pero considerando la información objetiva y «fundada».

Es interesante reparar en que esta Relación individual de las operaciones de la Escuadra Francesa narra los sucesos como lo haría una persona que o bien estuvo allí o ha recibido la información de muy buena mano, dando pormenorizada noticia de las maniobras de los barcos implicados y sus posiciones, especificando su nombre, número de cañones con los que contaban y otros detalles que hacen pensar que el autor o bien es un miembro de la Armada española o está muy próximo a ella. Un motivo que explicaría el prudente anonimato con el que se ha protegido. Pues esa persona, que ha debido tener acceso a la información, a todas luces, de fuentes oficiales, la ha redactado, la ha mandado imprimir y la ha puesto a la venta. ${ }^{2}$

Por otra parte, también es importante detenerse a observar cómo la noticia, a pesar de su carácter naval, utiliza una retórica en términos religiosos que habla de combate entre «cristianos» $\mathrm{y}$ «musulmanes», refiriéndose, por ejemplo, al Rey de Francia como «Su Majestad Cristianísima» (p. 3), a la acción bélica narrada como «campaña fructuosa para la Cristiandad» (p. 7), y al Emperador de Marruecos y los suyos como «moros» (p. 6) o «enemigos de la Santa Fe» (p. 7). Y es oportuno reparar en ello porque esa retórica es la misma que la que aparece como trasfondo en la tragedia Combates de amor y ley, publicada ese mismo año. Una circunstancia que nos sirve para desterrar la hipótesis según la cual las referencias a combate religioso y cautivos que aparecen en esa tragedia serían un indicio de que su autor debió ser un fraile o un hombre de la iglesia. Pues son las mismas que aparecen en otros muchos textos de la época, incluso escritos oficiales de la mismísima Armada española, y se encuentran igualmente en el otro impreso que nos interesa, al que enseguida haremos referencia.

Y es que la amenaza norteafricana, como la llama J. A. Gallego, era en esos momentos un peligro real que acechaba al comercio y a los viajeros que hacían rutas marítimas, especialmente por el Mediterráneo, aunque también en el Atlántico, debido a los constantes ataques de barcos que son calificados en los escritos españoles indistintamente como «musulmanes» $\mathrm{o}$ «moros; y que cuando se describen sus acciones, lo son siempre en términos de conflicto entre religiones. Dicho con sus propias palabras: «la enemistad secular, que tenía razones religiosas, entre muslimes y cristianos, perduraba de forma virulenta en pleno siglo XVIII [...], constituía un peligro constante para los que navegaban entre las dos penínsulas. Las noticias de este tenor se repetían en las costas y el asunto inquietaba de continuo» (Gallego, 2003: 384). ${ }^{\mathrm{r}}$

En mi opinión, la persona que escribió el texto sobre el ataque de la Escuadra francesa en junio de 1765 o es la misma que había escrito ya en esa fecha Combates de amor y ley (la obra, extensa y en verso, tenía que estar lista, puesto que se publicó ese mismo año), o está muy próxima a ella. Allí, al comienzo del Acto III,,$^{14}$ por ejemplo, hace decir al turco Otomán que no se siente amenazado por la Armada francesa porque sabe de la mano de

II No 30, pp.. 236-238. La noticia está fechada en Cádiz el I5 de julio de 1765

I2 Véase más adelante la nota I5.

I3 La noticia a la que se refiere este investigador es otra diferente que la que nosotros comentamos aquí.

I4 Cádiz, Imprenta Real de Marina, I765, p. 53. He utilizado el ejemplar que está disponible en versión digital en el Fondo Antiguo de la Biblioteca Universitaria de la Universidad de Sevilla, accesible aquí: https://bit.ly/2vSP $3 q \mathrm{G}$ y también desde la Biblioteca Virtual Miguel de Cervantes. 
buenos informantes que esa Armada está ahora en otros lugares del Mediterráneo. Pero no son las similitudes textuales entre ambos escritos lo que me permiten vincularlos: el principal aval a esta suposición es la relación existente entre este impreso de 1765 y otro anterior, publicado en la misma Imprenta Real de Marina en I758, que daba también noticia de otro combate contra los «moros», pero en cuyo título mismo se hace referencia a un «del Postigo», en este caso, «Isidoro», un oficial de la Armada española que había participado en una de estas acciones y que pertenecía a una familia andaluza de la nobleza napolitana del Rey Carlos.

Retomo, pues, la línea principal de mi argumentación: para conocer quién está detrás de La Pensadora (y de la tragedia Combates de amor y ley), hay que poner en relación nuestro periódico no solo con la tragedia, sino con dos folletos de noticias salidos de la misma imprenta: uno, el que ya hemos comentado, publicado en I765; y el otro, en I758, antes, por tanto, de que viese la luz La Pensadora Gaditana. Este último es un impreso, igualmente anónimo ${ }^{15}$ en el que podemos de nuevo observar la utilización de la misma retórica religiosa arriba aludida para hablar de las escaramuzas con el corso norteafricano. $Y$ que en su extenso y significativo título facilita el nombre que nos permite vincular un tercer texto —además de La Pensadora y Combates - a un «del Postigo». Se trata de la noticia (casi inmediata: el hecho narrado ocurre el 9 de junio, y el impreso lleva fecha de ocho días después) Relación del combate que tuvieron los navios Soberano, Vencedor y Héctor, del mando del Capitán de esta clase Don Isidoro del Postigo, que montaba el primero, en el día 9. del corriente, estando N. S. con Torre-Molinos, en distancia de 9. a Io. leguas, con la Capitana de Argel, nombrada El Castillo Nuevo, del porte de 60. cañones de los calibres de I8. I2. y 8., siendo su comandante el Arráez Mahamud Rais. Y con la fragata también argelina, nombrada La Caravela, del porte de 4o. cañones, y su comandante Archi-Mostafá, Renegado. Lleva fecha, al final del texto, dada en "Cádiz, y junio I7. de I758»; y se imprimió, como ya se ha dicho, en la misma Imprenta Real de Marina de Don Manuel Espinosa de los Monteros, ${ }^{16}$ al igual que lo serían después La Pensadora, Combates de Amor y ley y la Relación individual de las operaciones de la Escuadra francesa.

D. Isidoro García del Postigo y del Prado, o también, indistintamente, D. Isidoro del Postigo, era en ese momento un Capitán de Navío de la Armada española, que con el tiempo llegaría a ser Jefe de Escuadra y «uno de los generales más notables de nuestra Marina Real en su época» (Fernández Duro, 1897 y ss.). ${ }^{17}$ Había nacido en Écija (Sevilla) en I703 y se había formado en la primera promoción de la Real Compañía de Caballeros Guardias Marinas de Cádiz, en la que entró en I717 (Válgoma, 1943: 2I). Era hijo de un heroico militar con una amplia hoja de servicios, D. Juan García del Postigo, primer

I5 Nada que ver, por tanto, con un tercer impreso relativo a otra batalla naval que se publicó en I755 en la misma imprenta, que lleva el nombre del autor. Con una redacción diferente a los dos anónimos aquí estudiados, relata una acción heroica de Don Josef de Flon y Sesma, Capitán de Fragata de la Real Armada: Diario del combate, que sobre la Rada de Benidorme (sic), o barlovento de Alicante, tuvieron los cinco javeques del Rey, mandados por Don Joseph de Flon y Sesma, Capitán de Fragata de la Real Armada, y Sub-Comandante de los Batallones de Marina del Departamento de Cartagena. El autor es el mismo protagonista. Al final del relato se indica: «Es copia de la original. Cádiz, y abril 28. de I775". Es decir, se está dando a la imprenta una copia del informe oficial, la relación original de los hechos realizada para la Armada. Y por eso se ha añadido: "Con Licencia del Excmo. Sr. Marqués de la Victoria», esto es, de la autoridad máxima de la Armada en Cádiz. En los otros dos impresos, en cambio, la noticia es periodística y anónima, un relato que no aparece como oficial, pero que claramente ha sido tomado de un informe oficial.

I6 He utilizado, igualmente, el ejemplar que se encuentra disponible en la Biblioteca Virtual de Andalucía. La información facilitada en este impreso sobre la batalla es de nuevo muy precisa, con indicación del número de disparos realizados por los barcos y otros aspectos interesantes para el público.

I7 Citado por Isidoro Vázquez de Acuña y García del Postigo en la entrada «Isidoro García del Postigo y del Prado", de la que es autor, en la edición electrónica del Diccionario Biográfico de la Real Academia de la Historia: https://bit.ly/2MQoOHR. Última consulta, 6 de agosto de 2018. Esta entrada es muy completa y da mucha información sobre el marino en cuestión. 
Marqués de García del Postigo, ${ }^{18}$ un título que le había concedido en 1736 el futuro Rey de España Carlos III por su valiente actuación en la recuperación de Nápoles. ${ }^{19}$ En el año en que se publica el impreso, D. Isidoro García del Postigo había pasado ya de su destino en Cádiz a uno nuevo en Cartagena, desde donde se inició la acción descrita en el folleto, a pesar de lo cual la noticia se publicó en Cádiz, donde vivía el resto de su familia directa. Puede comprobarse en su hoja de servicios y otra documentación que lo narrado corresponde a una noticia real ${ }^{2 \circ}$ de Isidoro García del Postigo, aunque aparezca el apellido abreviado en el impreso al que hacemos referencia. Como también lo hace la Gaceta de Madrid de 20 de junio de $1758\left(\mathrm{n}^{\mathrm{o}} 35\right),{ }^{2 \mathrm{r}}$ al relatar la misma noticia.

El año en que se publica el relato de esa acción heroica, 1758 , el nuevo Marqués de García del Postigo (el III) lo es ya su sobrino Diego García del Postigo y Manrique de Lara, también perteneciente a la Armada española, que vive en Cádiz. Al fallecer el padre de Isidoro por heridas de guerra en Bolonia (Italia) en el año I743, el título de Marqués lo hereda su hermano mayor, Francisco, excelente marino que había pertenecido también, al igual que su hermano Isidoro, a la primera promoción de la Real Compañía de Guardias Marinas de Cádiz, llegando a ser Piloto Mayor de la Armada..$^{22}$ Pero Francisco García del Postigo y del Prado, II Marqués de García del Postigo, nacido igualmente en Écija en I700, había fallecido prematuramente en Cádiz, donde residía con su familia, en I755, dejando una viuda y tres hijos. Los dos varones, Diego, el que hereda el título por ser el mayor, y Juan, nacidos ambos en El Puerto de Santa María (Cádiz), ${ }^{23}$ eran igualmente miembros de la Armada, y el segundo de ellos había estado también en la acción naval descrita en el escrito que menciona a su tío, donde había resultado herido.

Estas informaciones sobre los dos impresos citados me llevaron a poner en relación el «del Postigo» del supuesto autor de Combates de amor y ley con esta familia de prestigiosos miembros de la Armada de apellido «del Postigo», o "García del Postigo», residentes en Cádiz en esos años: tanto con la primera generación, los apellidados García del Postigo y del Prado, a la que pertenecieron los aludidos Francisco, Isidoro y Juan (este último, conocido, entre otras cosas, por haber sido propuesto, por su valía científica, siendo un joven Guardiamarina de Cádiz, ${ }^{24}$ para representar a España en la expedición de la Real Academia de Ciencias París que debía medir el meridiano en América, junto con Jorge

I8 En otras ocasiones aparece como Marqués de Casa García del Postigo, o, más brevemente, Marqués del Postigo.

I9 El título, para él y todos sus descendientes legítimos, le fue otorgado mediante la Real Orden de 3 de mayo de I736, con Real Carta de Creación dada en Nápoles el i de junio de i736. Cf. Vázquez de Acuña y García del Postigo $(D B e)$.

20 «Famoso fue el combate que sostuvo en crucero sobre Cabo de Palos, en los mares de Málaga, el 9 de junio de 1758 , al mando de los navíos Soberano, Héctor y Vencedor» (Vázquez de Acuña y García del Postigo, DBe). También puede verse al respecto Fernández Duro: «Morería» (I897 y ss: VI, 4I6); o consultarse igualmente lo narrado al respecto de esa batalla en la biografía «García del Postigo (Isidoro)» que firma Francisco de Paula Pavía (I873: II, 36-37), es un libro en el que hay diversos colaboradores.

2I «Por Extraordinario, despachado de Cádiz por el Marqués de la Victoria, Gobernador de la Armada, se ha tenido noticia de que los navíos Soberano, Vencedor y Héctor, del mando de D. Isidoro del Postigo, lograron encontrar en los mares de Málaga, el 9 del corriente, a el navío Castillo-Nuevo, Capitana de Argel, y una fragata, que el primero, después de una obstinada resistencia, se rindió en tal estado, que se fue a pique, dando solo tiempo a recoger 306 turcos y 56 cautivos, resto de su tripulación de más de 500, y que la fragata, separada de su Comandante desde el principio de la acción, y seguida por el navío Héctor, se le ocultó en la noche, a favor de una turbonada, no obstante tenerla ya desarbolada de un mastelero» (p. 200).

22 Un puesto que después pasó a llamarse Comandante en Jefe del Cuerpo de Pilotos.

23 Según los textos de la época, El Puerto de Santa María estaba a dos leguas por mar y seis por tierra de la ciudad de Cádiz. La distancia actual por carretera es de $27 \mathrm{~km}$, y en línea recta de $12.76 \mathrm{~km}$.

24 Nacido en Écija en I7ı7, se le tomó asiento en la Real Compañía de Caballeros Guardias Marinas de Cádiz el I9 de enero de I73I. 
Juan²); pero también con la segunda generación, Diego y Juan García del Postigo y Manrique de Lara. Sin embargo, al no contar con las partidas de bautismo, no podía saber si alguno de ellos tenía un segundo o tercer nombre que me permitiese relacionar, bien a Francisco (aunque hubiese fallecido ${ }^{26}$ ), bien a algunos de los dos llamados Juan, con el «Juan Francisco» al que se le atribuye la tragedia en cuestión. Y así, con el convencimiento de que es alguien de esta familia quien está bajo las publicaciones (pues contamos también con el detalle interesante de que la edición de La Pensadora que se realiza en I768 se le encargue precisamente a un impresor del Puerto de Santa María, ${ }^{27}$ donde no solo se había casado Francisco sino que era además la localidad natal de su esposa y dos de sus hijos), seguí investigando en otra dirección.

Me planteé entonces directamente la cuestión de si alguno de ellos podría haber escrito La Pensadora Gaditana, dado que las características de esa publicación exigen una estancia con continuidad en Cádiz durante el período en que fue apareciendo semanalmente (cosa que no ocurre con la tragedia, que se habría podido escribir fuera de Cádiz y publicarse después en ella cuando se volvió a casa). Pero si se miran con detalle las hojas de servicios prestados a la Armada por esos marinos, ninguno está en Cádiz con constancia durante ese período: Francisco ha fallecido, como hemos dicho, Isidoro vive en Cartagena desde que se casó allí en $1747,{ }^{28}$ Diego ha sido destinado a esa misma ciudad en $\mathrm{i} 762, \mathrm{y}$ los dos de nombre Juan, tío y sobrino, aunque viven en Cádiz, son solteros y están en continuo movimiento debido a los constantes viajes y las acciones militares en que intervienen, pasando largas temporadas fuera. ${ }^{29}$ Esto y una segunda circunstancia, la de que cuando se tramitó la edición de 1786 estuviesen ya todos ellos fallecidos, me llevó a hacerme la pregunta de una manera diferente: ¿quién, de esa familia, estuvo con continuidad en Cádiz entre I763 y I764 y vivía aún en I784, cuando se solicita la licencia para la publicación de La Pensadora Gaditana como libro ${ }^{30}$ ? Y la respuesta, que abre una vía de investigación muy interesante y permite hacer una hipótesis verosímil y fundada sobre la autoría del periódico, es esta: Beatriz Manrique de Lara Alberro, Marquesa viuda de García del Postigo, o simplemente, Marquesa «del Postigo», esposa de Francisco, cuñada

25 Finalmente no pudo salir con la expedición, porque el barco con el que venía de América como piloto del mismo se retrasó más de lo esperado y tuvo que ser sustituido. Cf. Miguel Sanz (2013: 125).

26 Podría ser, por ejemplo, una publicación póstuma.

${ }_{27}$ La impresión se hace en la oficina de Cádiz de Don Francisco Rioja y Gamboa, impresor del Puerto de Santa María. A propósito de este impresor como uno de los de esta última localidad, cf. Francisco Aguilar Piñal (I986: IV, 924). De esta reimpresión (así aparece en la licencia inicial) de La Pensadora, solo conocemos dos únicos ejemplares, los correspondientes a los tomos I y in de La Pensadora. Se encuentran en la Biblioteca de Catalunya, ref. R (3)-8-25I para el tomo i y R (3)-8-252 para el tomo II. Pertenecieron a «D. Pau Pons y Pons», según indican las anotaciones manuscrita en los ejemplares. El comerciante Pau Jaume Pons, de Mataró, se registra en Cádiz el 26 de marzo de 1753 en la Matrícula de Comercio de la Universidad de Cargadores a Indias, para comerciar con América. Cf. C. Martínez Shaw (I98r: I08) o F. Costa Oller (I988: 72). La familia Pons comerció con América sola, pero también más tarde asociándose con franceses («Roland y Pons») y con alemanes («Pons y Ziegler»).

28 Vivió allí desde su matrimonio el 25 de marzo de 1747 con Ana Luisa del Poyo y Maya, con la que tuvo tres hijos, que también fueron relevantes oficiales de la Armada, y una hija, casada a su vez con otro oficial de la Marina española. Véase la interesante y completa nota 5 del artículo del Coronel Juan Antonio Gómez Vizcaíno (20I4: 25). No he tenido en cuenta a estos marinos García del Postigo, hijos de D. Isidoro, porque eran pequeños cuando se publicó La Pensadora.

${ }_{29}$ Pueden verse las biografías detalladas de todos ellos, con todos las circunstancias de su actividad en la Marina, en la versión electrónica del Diccionario Biográfico Español de la Real Academia de la Historia, realizadas por el investigador Isidoro García del Postigo y Vázquez de Acuña, miembro de esa ilustre familia y experto en genealogía.

30 Según consta en el expediente que se conserva en el Archivo Histórico Nacional, si bien la obra aparecería finalmente dos años más tarde, en I786: «Licencia de impresión en cuatro tomos de la obra La Pensadora Gaditana, de Beatriz Cienfuegos, solicitada por el impresor Manuel Jiménez Carreño». Fecha de formación del expediente: I784/I785. Signatura: AHN, Consejos, leg. 5548, exp. IO3. 
de Isidoro y Juan, y madre de Diego, de Juan y de una hija llamada Francisca que tiene dieciséis años cuando se escribe La Pensadora.

Los García del Postigo constituían, ciertamente, una prestigiosa familia de militares, funcionarios públicos muy comprometidos con la Patria, a los que el título de Marqués les había llegado por sus heroicos méritos. Estuvieron siempre muy vinculados a Carlos III, que no solo les había otorgado el título familiar, sino que les haría después la gracia de otras prerrogativas, como cuando le concedió al ya citado Isidoro García del Postigo y del Prado que sus hijos Isidoro y Antonio pudiesen entrar en la Real Compañía de Guardias-Marinas de Cádiz antes de tener edad para ello, en agradecimiento a los servicios prestados. Pero los Manrique de Lara no les iban a la zaga. Así, en I717, , $^{3 \mathrm{~T}}$ en la solicitud que el padre de Beatriz Manrique de Lara Alberro realiza para acceder al puesto de Gobernador de Puerto Longón en la Isla de Elba, donde ya estaba destinado como Teniente del Rey, alguien anota a mano, como puede verse en el expediente conservado en la Diputación Foral de Navarra: «Es el recomendado de Su Alteza de Parma».32 Así, en I718 lo vemos ya Gobernador del citado Puerto, un enclave estratégico esencial para las posiciones de España en el Mediterráneo. ${ }^{33} Y$ esto antes de que tres de sus hijas y una nieta acabaran siendo camaristas de las sucesivas Reinas de España. ${ }^{34}$ Beatriz Manrique de Lara Alberro pertenecía también, pues, por sí misma, a una familia culta, comprometida con el país y muy vinculada a la casa real española.

Beatriz había nacido en el Puerto de Santa María Cádiz entre I7II, fecha de nacimiento de su hermana Francisca, ${ }^{35}$ la inmediatamente mayor a ella, y I7I6, año en que vino al mundo su hermana Inés, ${ }^{36}$ la siguiente menor; con lo que se puede establecer como fecha bastante aproximada para su nacimiento el año de I7I4. Era la cuarta de nueve hermanos, hijos de D. Diego Antonio Manrique de Lara Ocio (Caballero de la Orden de Santiago, que llegaría a ser Mariscal de Campo de los Reales Ejércitos), nacido en Nájera y bautizado en la Parroquia de Santa Cruz el 24 de octubre de i668);37 y de Da Josefa Alberro Lucas ${ }^{38}$ (nacida en San Sebastián, y bautizada en la parroquia de Santa María

3I Carece de fecha, pero indica que empezó a servir al Rey en i689 y que lleva más de veintiocho años.

32 Puede verse la solicitud que hizo para esta plaza de Gobernador, en el Archivo de la Diputación Foral de Álava, signatura ATHA-DAH-FVAR-ooI-oI2-22, donde resume brevemente su trayectoria militar desde sus comienzos. La anotación se encuentra en el último folio, el número 3.

33 Según Cristina Borreguero Beltrán (200r: 175), era una base estratégica importantísima en toda la política hispanoitaliana del siglo xviII.

34 De Isabel de Farnesio, de Bárbara de Braganza, de María Amalia de Sajonia, e incluso de María Luisa de Parma cuando era Princesa de Asturias.

35 Así consta en el expediente de acceso a la Orden de Carlos III de un hijo suyo, donde puede consultarse una gran parte de la información relativa a esta familia: partidas de bautismo, testamentos, matrimonios, etc. Se trata del expediente de pruebas de Diego Antonio Carrillo Manrique de Lara Carrión y Alberro, Marqués de Alcocebar y Coronel del Ejército (cf. PARES. Portal de Archivos Españoles, «Expediente de pruebas del caballero de la Orden de Carlos III Don Diego Antonio Carrillo Manrique de Lara Carrión y Alberro». I784. Signatura: AHN, Estado-Carlos III, Exp. 202).

36 Puede verse el expediente de pruebas de Inés Manrique de Lara y Alberro al casarse con un Caballero de la Orden de Santiago: PARES. Signatura: AHN, Órdenes Militares-Casamiento Santiago, Exp. I0242.

37 Así aparece en el ya mencionado expediente de acceso a la Orden de Carlos III de su nieto Antonio Carrillo Manrique de Lara, hijo de Francisca. La partida de bautismo de D. Diego Antonio Manrique de Lara y Ocio está reflejada en la p. I47. Otra información interesante sobre este militar, padre de Beatriz Manrique de Lara y Alberro, son dos documentos que se encuentran en el Archivo Histórico de la Diputación Foral de Navarra: uno es la solicitud ya citada que hace en 1717 para ser nombrado Gobernador de Puerto Longón, una vez que se ha producido una vacante, y en el que hace una exposición de todos los servicios que ha prestado al Ejército español desde que comenzó a servir en él en Flandes en I689 y hasta esa fecha; el otro documento es la certificación que se le expide de los servicios prestados en Flandes (signatura ATHA-DAH-FVAR-oooI-006-05).

38 En otros lugares, Josefa Alberro (o de Alberro) Lucas y Lauzurrica, utilizando como tercer apellido el segundo de su madre, Vicenta de Lucas Ladecurrica. 
el 2 de febrero de I68I), que contrajeron matrimonio en Ceuta en $1707.39 \mathrm{El}$ orden de mayor a menor de los hijos que tuvieron es este: Diego Antonio, María Josefa, Francisca, Beatriz, Inés, Juan Manuel, Margarita, Teresa y José Antonio.

Fue una familia cosmopolita y culta que viajó mucho debido a la profesión militar del padre, acompañándolo a donde lo destinaban. Así, por ejemplo, Francisca, nació en Ceuta, Inés, en Puerto Longón, Margarita, en Almería, y Beatriz, en el Puerto de Santa María (Cádiz). Sin embargo, esta última quedó muy pronto vinculada al lugar en el que había nacido y habría de casarse veinte años más tarde, según se desprende de un interesante comentario que hace su padre en el poder para testar que realiza en I724, cuando ella tiene solo unos diez años, y sobre el que volveremos más adelante. Sea como sea, las mujeres de esta familia debieron recibir una buena educación, puesto que tuvieron a lo largo del siglo xviII una extraordinaria vinculación con la familia real española. Como ya adelantamos, al menos tres de la hermanas de Beatriz Manrique de Lara, Josefa, Francisca e Inés, fueron camaristas de las sucesivas Reinas de España, casándose con hombres cultos y de prestigio: Josefa, con Agustín Montiano y Luyando en I734, que cuatro años más tarde sería el primer Director de la Real Academia de la Historia; ${ }^{\circ}$ Francisca, en I740, con Nicolás Carrillo de Mendoza y Carrión, Marqués de Alcocebar; ${ }^{44}$ e Inés, en I734, con Juan Antonio Valenciano Alonso, Caballero de Santiago, Oficial de la Secretaría del Despacho Universal de la Marina, Consejero de Su Majestad y Secretario de Cámara en el Consejo Supremo de las Indias, cuyo primer hijo fue apadrinado por los Reyes Felipe V e Isabel de Farnesio. ${ }^{42}$ Pero es que incluso la propia hija de Beatriz, Francisca, nacida en Écija en I747, sería camarista de la Reina Madre Isabel de Farnesio y de la Infanta de Asturias María Luisa de Parma (esto último, entre 1770 y I777, un puesto que dejó para casarse ${ }^{43}$ ). El propio Carlos III apadrinaría al primero de sus hijos (y primer nieto de Beatriz Manrique de Lara), haciéndole además, entre otros regalos en dinero, el muy personal de «un aderezo de diamantes y esmeraldas».44

Beatriz Manrique de Lara Alberro se casó con Francisco García del Postigo y del Prado en el Puerto de Santa María, el 30 de agosto de 1734, donde nacieron, como ya dijimos, su dos primeros hijos, Diego, el ro de junio de I735, y Juan, el 3 de abril de I737, mientras que su hija Francisca lo hizo en Écija, el pueblo de su marido, el 20 de diciembre de 1747. En I743, a la muerte de su suegro, ${ }^{45}$ pasó ella misma a ser Marquesa de García del

39 En el expediente ya aludido relativo a Diego Antonio Carrillo Manrique de Lara, hijo de Francisca, se indica que en el libro donde aparecen las velaciones para el matrimonio de Diego Antonio y Josefa, los padres de Beatriz Manrique de Lara Alberro, primero se anota como fecha de las mismas el 27 de enero de I7II, en Ceuta (véase el folio 44). Y esta es la fecha que aparece en los trabajos de muchos investigadores. Pero si se sigue leyendo, más adelante se indica que otro sacerdote ha hecho en el libro una corrección entre líneas y ha señalado como año de las velaciones el 1707, cosa más acorde con el hecho de que la tercera hija de ese matrimonio nacería pocos meses después, en ese mismo año de İII, y que ya tenían otros dos hijos.

40 Cf. Rosalía Fernández Cabezón $(\mathrm{DB} e)$.

4I Se casó en el Palacio del Real Sitio de El Pardo el 5 de abril de I740. Su marido fue nombrado en ${ }^{175^{2}}$ Marqués de Alcocebar precisamente en agradecimiento a los servicios prestados por su esposa a la familia real. Según Javier Barriento Grandón, fue «corregidor de Alcalá, Loja y Alhama, y de la ciudad de Jerez de la Frontera y superintendente de sus rentas reales» ( $D B$ e, biografía de su hijo Diego Antonio Carrillo y Manrique).

42 Joseph Antonio Álvarez y Baena: «Juan Antonio Valenciano», en su libro Hijos de Madrid, Ilustres en santidad, dignidades, armas, ciencias y artes. Diccionario bistórico por el orden alfabético de sus nombres, Madrid, Oficina de D. Benito Cano, I79o, t. III, pp. 303-304.

${ }_{43}$ Con Joaquín de Aróstegui y Escala, futuro Marqués de García del Postigo a partir de I783, en cuanto consorte de Francisca y por fallecimiento del hermano de esta.

44 I. Vázquez de Acuña y García del Postigo, en la entrada que dedica a esta hija de Beatriz Manrique de Lara en el $D B e$. Es de suponer que, dado el trato tan estrecho que tiene con su hija Francisca, el Rey Carlos III debía conocer también a Beatriz Manrique de Lara Alberro, que era viuda, madre y cuñada de miembros de la Armada, los del Postigo, muy próximos a él y pertenecientes a su nobleza napolitana.

45 Como ya indicamos, en Bolonia (Italia), por heridas de acción bélica, el 23 de enero de 1743 . 
Postigo, como consorte del heredero, Francisco. Tras el fallecimiento de este en 1755 en Cádiz, cuando la familia ya vivía allí, pasó a ser la Marquesa viuda, mientras que sus hijos fueron heredando uno tras otro el título debido a sus muertes prematuras: primero sería Marqués Diego, soltero, que fallecería en 1765 , después su hijo Juan, también soltero, que moriría en I780, y finalmente, Marquesa su hija Francisca.

En r763, cuando se empieza a publicar en Cádiz La Pensadora Gaditana, Beatriz Manrique de Lara Alberro vive con su familia en Cádiz y está viuda. Por las Capitulaciones matrimoniales podemos conocer qué propiedades aportó al matrimonio, pero no qué quedaba de ellas a esas alturas. Otorgadas en el Puerto de Santa María el 8 de agosto de I734 ante el escribano Pedro del Castillejo, poco antes de la boda, reflejan que ella aportó de dote «dos mil pesos escudos de ocho reales de plata, poco más o menos que lo que importa la ropa de su uso y prendas de adorno", mientras que el novio ofreció en arras 6.00o ducados de vellón en la décima parte de los bienes libres que poseía. La Marquesa García del Postigo poseyó un tercio de una propiedad en Nájera, que compartía con Don Luis Cistué y Doña María Josefa Carrillo y Abarca, que consistía en la viña de Somalo, de ro obradas, la viña del Parral, de I7, Avutarda de 23.5 pieza de avutardas y la mitad de la Casa Principal, cuyo valor total era de 13.735 reales y 2I maravedíes» (Vázquez de Acuña, 2008: 96).

No sabemos qué propiedades pudo acumular el matrimonio antes de que Francisco García del Postigo falleciese. Sí podemos imaginar que a partir de 1755 Beatriz Manrique de Lara vería mermada su capacidad económica, puesto que había perdido el sueldo de su marido y se había quedado con dos jóvenes hijos marinos de dieciocho y veinte años y una niña de ocho. Debió contar con algún tipo de ayuda de la Armada, de la que seguramente viviría, pero tuvo que ser exigua, por lo que explicaré más abajo. Si buscó completar sus ingresos con algunas publicaciones, eso sería coherente con su estado y situación, como también lo sería que se hubiese ocultado, bien en el anonimato, bien bajo pseudónimos, o quizá utilizando ambas estrategias a la vez. Pues en algunos casos, tener otros ingresos era motivo suficiente para perder la ayuda a la que se tenía derecho, como ocurría cuando la viuda volvía a casarse, sobre todo entre las de oficiales de alta graduación, a las que no se suponía tan necesitadas. ${ }^{46}$

En realidad, cuando enviudó Beatriz Manrique de Lara en I755 no había aparecido aún el Montepío Militar (de I76r), que aseguraba a las viudas de los oficiales una pensión, si bien existía desde 1717 una partida anual para ayudarlas en algo, aunque era exigua. Es probable, no obstante, que Beatriz Manrique de Lara, dada la relevancia de su marido, recibiese, como ya he dicho, alguna aportación monetaria de la Armada tras enviudar, aunque el principal respaldo de la Marina fue el ascenso que le hicieron enseguida a su hijo Diego a Alférez de Fragata, pasando así de suboficial a oficial, con lo que mejoraría en algo la situación económica familiar. Sin embargo, en I762. Diego deja Cádiz (y la casa familiar) por haber sido destinado a Cartagena, y más tarde, en I765, fallece a resultas de las heridas en un combate naval contra los corsarios norteafricanos en las aguas de Ibiza. ${ }^{47}$ La situación económica de la familia seguramente empeoró tras ello.

Ciertamente que Beatriz Manrique de Lara debió percibir una pensión por este hijo, y muy probablemente incluso se le permitiera acumular las dos ayudas, la del marido, que sería más escueta, y la del hijo, pues esta última caía ya bajo lo estipulado por el Montepío Militar, que era más generoso. Pero varias circunstancias complicaron de seguro

46 Para toda la información que utilizo aquí relativa no solo al Montepío Militar, sino a otros que hubo en la Armada, cf. César Herráiz de Miota (2005). No soy una experta en estas cuestiones de los montepíos.

47 Falleció el siete de septiembre de ese año, el mismo en el que se publicaron Combates de amor y ley y la noticia sobre el combate naval de la Escuadra francesa. 
su economía de nuevo más adelante: entre ellas, los preparativos hacia I768 para que su hija Francisca fuese de camarista a Madrid, y sobre todo un triste asunto, del que los investigadores no encuentran el motivo, por el que su hijo Juan se verá en torno a I770 degradado y encarcelado en Cádiz, pasando a ser de nuevo un suboficial del menor rango, después de haber llegado a Capitán de Navío y Caballero pensionado de Carlos III. Bache que superará entre otras cosas por la protección que gozaba del Monarca, que lo destinó a La Luisiana, donde fallecerá en Nueva Orleans el 27 de agosto de 1780 con el grado de Subteniente. Todos estos datos los expongo aquí, entre otras cosas, porque es curiosa la correlación existente entre los periodos en que podemos suponer dificultades económicas en la vida de Beatriz Manrique de Lara y las tres impresiones que se hacen de La Pensadora Gaditana.

Sea como sea, es verosímil que en I780, cuando falleció Juan, su madre ya no pudiese cobrar nada por él. No solo porque las condiciones se endurecieron a medida que avanzaba el siglo, y solo se pudo, en muchos casos, disfrutar de una pensión, la de mayor cuantía. Sino por la reclamación que hace su hermana en $1790,4^{8}$ diez años más tarde del fallecimiento de Juan, de los «sueldos vencidos» y cualquier otro importe en la «Caja del Regimiento» al que pudiera tener derecho ella, una vez que ya es la única heredera. Y que nos va a ser de utilidad para establecer una aproximación al año de fallecimiento de Beatriz Manrique de Lara Alberro.

Este último expediente de reclamación de «sueldos vencidos» da ya por fallecida a Beatriz en dos documentos pertenecientes al mismo, fechados en I79o. No se indica cuándo ha muerto, pero sí algo curioso: que su hija Francisca es ya en ese momento Marquesa de García del Postigo, título que posee desde hace siete años, al heredarlo, previa reclamación, tras el fallecimiento de Juan, que era el que lo poseía en el momento de fallecer; pero que sin embargo, no ha podido reclamar hasta ese momento, siete años más tarde, heredar esos «sueldos» de su hermano. Cosa explicable, desde mi punto de vista, porque mientras que su madre no era heredera del título, sí lo era de los «sueldos» de Juan, pues la heredera de un soltero era la madre del mismo. Lo que nos permite suponer que Beatriz Manrique de Lara debió fallecer ca. 1790. Ahora bien, ¿por qué Beatriz no había reclamado esos importes de «sueldos vencidos» $\mathrm{y}$ otros emolumentos que pudiese haber en la «Caja del Regimiento» tras el fallecimiento de su hijo en I780? Como he indicado más arriba, muy probablemente porque no pudo acumular ya más ayudas; es más, es posible que incluso lo solicitara y no se le concediese, como tampoco debió de permitírsele percibir nada de su cuñado Juan, soltero, fallecido en I78r. Sea como sea, lo cierto es que no lo cobró y por eso pudo su hija Francisca —en realidad, su marido, como era exigido- solicitar cobrarlos en nombre de su propio hijo, cosa que se le concedió, una vez acreditado el fallecimiento de su padre y su madre. El motivo por el que este asunto importa aquí es evidente: si Beatriz Manrique de Lara falleció ca. I79o, ello es coherente con el hecho de que en 1784 todavía «Beatriz Cienfuegos» estuviesen viva, puesto que solicitó la tercera impresión de La Pensadora Gaditana.

Hago referencia ahora, para acabar, a la última cuestión sobre la que he encontrado información en la documentación y que abre una vía para seguir trabajando. Como he indicado más arriba, en el poder para testar en su nombre que hace su padre a su madre en $\mathrm{I} 724$, hay un interesante inciso cuando autoriza a esta para que «[...] nombre por mis universales herederos a D. Diego Antonio, $D^{a}$ María Josefa, $D^{a}$ Francisca, $D^{a}$ Beatriz, que ésta está en el Puerto de Santa María, Da Inés, D. Juan Manuel, Da Margarita, Da Teresa

48 Puede verse en PARES: «Juan García del Postigo. Sueldos». Archivo General de Simancas, Secretaría de Guerra, leg. 6916, Iо. 
y D. José Antonio Manrique y Ocio mis hijos legítimos y de la dicha Da María Joserfa Alberro, mi legítima mujer».49 Dado el carácter solemne del documento, no parece que el comentario referente a que Beatriz está en el Puerto de Santa María aluda a una estancia circunstancial de un par de días, o en todo caso breve, porque en mi opinión, esto no se habría reflejado. La afirmación del padre parece referirse más bien a que esa hija concreta, de la única de la que se comenta algo, reside en el Puerto de Santa María, esto es, está allí de modo permanente y separada del resto de la familia.

Teniendo en cuenta que en ${ }_{72} 24$ Beatriz tiene diez años, solo existen dos posibilidades: o vivía allí con otros parientes, o estaba interna en algún convento, ${ }^{50}$ quizá, por ejemplo, el muy elitista de la Pura y Limpia Concepción, donde la dote que debía entregar la monja profesaba era prohibitiva, ${ }^{5 \mathrm{~T}} \mathrm{o}$ el del Espíritu Santo. En relación a este último, en concreto, sabemos que en el Seminario de Niñas Nobles que tenía anexo el Convento del Espíritu Santo de Sevilla las niñas entraban con una edad mínima de siete años y una máxima de diez, y, aunque desconocemos cuáles eran las condiciones en su homónimo de El Puerto de Santa María, este dato nos permite hacernos una idea sobre si Beatriz podría estar en I724, con diez años, en este u otro convento.

Esta posibilidad de que Beatriz estuviese en El Puerto de Santa María en un convento es importante porque en las páginas de La Pensadora Gaditana Beatriz Ciefuegos afirma haber pasado seis años en uno sin decidirse a profesar, dado que era más bien voluntad de sus padres que suya que siguiera la vida religiosa. Reconoce Cienfuegos que su buen conocimiento del latín y el resto de su formación cultural es el resultado de que sus padres le pusieron allí muy buenos maestros, que le dieron una excelente educación mientras ella iba demorando el profesar. Las razones que habrían llevado a unos padres a decidir dedicar a una hija a la vida religiosa tan pequeña pueden ser de muy variada naturaleza y se nos escapan, pero desde luego en una familia como la de los Manrique de Lara, donde al menos tres mujeres llamadas Beatriz fueron abadesas de convento, esa tradición podría haber dado alguna idea, como también la podría haber dado la sugerencia de alguien próximo, por ejemplo, Fray García (sic) Manrique de Lara, que se encuentra en esos momentos en un convento en Medina Sidonia (Cadiz) (Iglesias Rodríguez, 199r: 45I). Sea como sea, y con motivos para seguir investigando en esta dirección, el comentario del padre en el poder notarial pone de manifiesto que, a diferencia de su hermana Francisca, que nació en Ceuta, pero no quedó vinculada a esa ciudad, o de Inés, que tampoco quedó vinculada a Puerto Longón, a pesar de ver la luz allí, Beatríz además de nacer en E1 Puerto de Santa María, estaba allí en I724, se casó en esa localidad en I734, y allí tuvo a sus dos primeros hijos. Era, pues, andaluza y gaditana por nacimiento, por vivencias y por educación.

En las páginas del periódico La Pensadora Gaditana, la autora del mismo, Beatriz Cienfuegos, hace una construcción literaria de sí misma en la que hay muchos datos que coinciden — aunque juegue irónicamente a despistar - con la realidad de Beatriz Manrique de Lara Alberro. Dice de ella misma que es andaluza y gaditana (como Beatriz Manrique, que aunque no ha nacido en la ciudad de Cádiz, ha nacido en el cercano

49 Cf. el ya citado expediente de su nieto, en la p. 93.

50 Según el Catastro de Ensenada, unos veinticinco años más tarde, en I749, había en E1 Puerto de Santa María tres conventos femeninos: «el uno de Capuchinas y en él hasta treinta y cuatro religiosas, manteniendo cuatro donados para su servicio. El de la Concepción Franciscas (sic) Calzadas con cuarenta y cuatro religiosas, y dos sirvientas. E1 del Espíritu Santo Agustinas Descalzas (sic) con veinte y cinco religiosas, y dos sirvientas». Está en el folio 995 del informe sobre esta localidad, en Archivo General de Simancas, Dirección General de Rentas, I ${ }^{\mathrm{a}}$ Remesa, Catastro de Ensenada, Respuestas Generales, libro no 562. Se puede consultar en PARES: http://pares.mcu.es/Catastro/.

5I Cf., por ejemplo, su Oración panegírica que publica en Cádiz, en los herederos de Cristóbal de Requena, en I729. Disponible igualmente en la Biblioteca Virtual de Andalucía. 
Puerto de Santa María y sí vive en ella), que su padre es montañés (como el de Beatriz Manrique $^{52}$ ), que está, en lo que respecta a la edad, entre «su Merced»y «y su Señoría», esto es, a mitad de vida (como Beatriz Manrique, que tiene unos cincuenta años en esos momentos), que vive sin la sujeción penosa de un encierro (no es monja), pero también sin la del matrimonio (ironiza con esto, y el lector acaba por entender —al menos, fue mi caso- que está soltera, pero la realidad es acertada: Beatriz Manrique está viuda). También hace una mención intrigante relativa a que ya ha publicado algo antes de empezar a mandar a la imprenta el periódico (comentario que fue el que me hizo mirar todo lo publicado antes y después de La Pensadora en la misma imprenta, gracias a lo cual encontré los aludidos impresos de noticias de escaramuzas navales), cosa que sería acertada si fue ella la que mandó a la imprenta la noticia de 1758 .

Igualmente, el periódico está lleno de referencias navales, lo que es coherente con el marco en el que Beatriz Manrique de Lara se encuentra, rodeada de miembros de la Armada, pero familia también de comerciantes (pertenece a la del Cargador de Indias del Puerto de Santa María Juan de Araníbar y Alberro). En un pensamiento concreto incluso hay una mención humorística a que ella es una Doña Beatriz «Cien fuegos» (sic, con las dos palabras separadas, la primera en mayúscula y la segunda en minúscula), broma con su apellido relativa a barcos, pues un barco pasaba a ser de primera, esto es, un Navío, si tenía cien cañones o más; ironiza, por tanto, con que se creyese un Navío (el Doña Beatriz) de gran capacidad guerrera (cien fuegos).53 Podríamos seguir citando muchas coincidencias más, como que la única localidad de la provincia de Cádiz —si no me falla ahora la memoria - que se cita en el periódico sea precisamente El Puerto de Santa María, cuando una dama menciona que su marido se fue para allá a despachar sus negocios; o que en sus páginas se bromee con la sorpresa sobre la modernidad de las gaditanas de una prima que llega procedente de un pueblo no pequeño de la Andalucía del interior, que puede ser perfectamente, por la descripción, Écija, de donde proceden los del Postigo. Es posible incluso que Beatriz Manrique de Lara, como su homónima Cienfuegos, se educara en un convento. Como también que se pusiese a trabajar como periodista para ser útil a su familia cuando llegaron las dificultades, sacando adelante un periódico con una gran conciencia profesional y una gran dignidad (siempre presente en el periódico la modestia de reconocer que no escribe por solo amor al arte, sino que es importante el dinero).

Hay muchas cosas que aún nos quedan por saber, pero hay otras muchas que sobre $L a$ Pensadora Gaditana ya sabemos. Démosle el lugar que se merece en el Cádiz cosmopolita, ilustrado y liberal a nuestra querida filósofa y periodista Beatriz Cienfuegos, ${ }^{54}$ alejándola de la imagen obsoleta de una Andalucía siempre arrodillada en los confesionarios. Y después, como decía el Cándido de Voltaire, vayamos a nuestro jardín, y trabajemos.

52 De hecho, el periódico de Nájera se sigue llamando Diario Montañés.

53 Broma que cobraba un valor añadido por el hecho de que en la Armada española no había barcos con nombres de mujer (según puede verse en los listados de barcos, de fácil acceso a los investigadores). Aparece en el Pensamiento VI, del Tomo I. Está en la pág. I32 de la edición de I786, cuando, expone un sueño que ha tenido, en la parte final del texto, dice: «me oculté cuanto pude; y volví a escuchar a la verdad que decía: Aquí está Doña Beatriz Cien fuegos, que engañada de cuatro bachillerías que conserva en la memoria, ha tenido atrevimiento para aspirar al honor de Escritora y reformadora de costumbres de su tiempo».

54 Cf. mi trabajo en prensa, "Republicanismo y liberalismo en el periódico La Pensadora Gaditana», que se publicará en breve con el resto de investigaciones presentadas al congreso internacional Storytelling in the European Spectators. Graz (Austria), Universidad de Graz, 30-noviembre-2 de diciembre de 2017. 


\section{Bibliografía CITADA}

Aguilar Piñal, Francisco (I986), Bibliografía de autores españoles del siglo XVIII, Madrid, CSIC, t. IV.

Barriento Grandón, Javier, «Diego Antonio Francisco Guillermo Carrillo y Manrique», en Real Academia de la Historia, Diccionario Biográfico electrónico: https://bit.ly/2w9JSSv. Última consulta, I2 de agosto de 2018.

Borreguero Beltrán, Cristina (200I), Del Tercio al Regimiento, Valencia, Sociedad Económica de Amigos del País.

Canterla, Cinta (1999), «El problema de la autoría de La Pensadora Gaditana», Cuadernos de Ilustración y Romanticismo, 7, pp. 29-54.

Costa Oller, Francesc (1988), Mataró al seglo XVIII, Mataró, Altafulla (citamos por la edición electrónica hecha por el autor en 20I2, disponible en academia.edu).

Dale, Scott (ed., intr.. y notas) (2005), La pensadora gaditana por Beatriz Cienfuegos, Newark, Juan de la Cuesta.

Fernández Cabezón, Rosalía, «Agustín Gabriel de Montiano y Luyando, El humilde», en Real Academia de la Historia, Diccionario Biográfico electrónico: https://bit.ly/2P8ugfk.

Fernández Duro, Cesáreo (I897 y ss.), La armada española desde la unión de los reinos de Castilla y Aragón, Madrid, Sucesores de Rivadeneyra.

Gallego, José Andrés (2003), «El pariente Mediterráneo y sus inquietantes vecinos», en El motín de Esquilache, America y Europa, Madrid, CSIC.

Gómez Vizcaíno, Juan Antonio (20I4), «El Teniente General Benito Spínola y Moro, Marqués de Spínola. Su período al frente del departamento marítimo de Cartagena de Levante (1753-1761)», Revista Historia Naval, no I26, pp. 23-52.

Hamann, J. G. (2015), Evocación de Sócrates, Huelva, Consulcom. Ed. crítica del texto alemán, traducción y notas de C. Canterla.

Herráiz de Miota, César (2005), «Los montepíos militares del siglo xvili como origen del sistema de clases pasivas del Estado", Revista del Ministerio de Trabajo y Asuntos Sociales $\mathrm{n}^{\mathrm{o}} 56$, pp. $177^{-206}$.

Iglesias Rodríguez, Juan José (I99I), Una ciudad mercantil en el siglo XVIII: El Puerto de Santa María, Granada, Muñoz Moya y Montraveta Editores.

Martínez Shaw, Carlos (I98I), Cataluña en la carrera de Indias (I680-I756), Barcelona, Crítica.

Pavía, Francisco de Paula (1873), Galería biográfica de los generales de Marina, jefes y personajes notables que figuraron en la misma corporación desde I700 a I868. Por el Vice-Almirante..., t. II, Madrid, Imprenta de J. López.

San Pío, Pilar y Carmen Zamarrón (I979), Catálogo de la colección de documentos de Vargas Ponce que posee el Museo Naval (Serie primera: Numeración romana I), vols. I y II. Madrid, Instituto Histórico de la Marina, CSIC.

Sanz, Miguel (2013), Breve noticia de la vida del Excelentísimo Señor Don Jorge Juan y Santacilia, Alicante, Universidad de Alicante. Ed. de Armando Alberola Romá y Rosario Die Maculet.

VÁlgoma y Díaz-Varela, Dalmiro de la (1943), Real Compañia de Guardias Marinas y Escuela Naval. Catálogo de pruebas de Caballeros aspirantes, Madrid, CSIC, Instituto Histórico de Marina, vol. I, p. 2I.

Vázquez de Acuña y García del Postigo, Isidoro (2008), «El linaje de García del Postigo (varonía Gálvez del Postigo)», Revista de Estudios Históricos (Chile), vol. 50, pp. 82-189.

—, «Isidoro García del Postigo y del Prado», en Real Academia de la Historia, Diccionario Biográfico electrónico: https://bit.ly/2MQOOHR

__, «Francisca de Paula García del Postigo y Manrique de Lara», en Real Academia de la Historia, Diccionario Biográfico electrónico: https://bit.ly/2Mr2 $\mathrm{QI}_{7}$. Última consulta, I2 de agosto de 2018. 